\title{
Support information: Metal Nanoclusters Modify the Band Gap and Maintain the Ultrathin Nature of Semiconducting Two-dimensional Materials
}

Fangzhi Yan, ${ }^{ \pm}$Chih-Kai Liao, ${ }^{\dagger}$ GuanHua Wu, ${ }^{\dagger}$ Stephan B. Bach,${ }^{ \pm}$Mahmoud A Mahmoud $^{ \pm+*}$

Department of Chemistry, ${ }^{ \pm}$Department of Biomedical Engineering \& Chemical Engineering, ${ }^{\dagger}$ The University of Texas at San Antonio, One UTSA Circle, San Antonio, $T X 78249$

*Mahmoud.abdelwahed@UTSA.edu 


\section{A. Synthesis of Nanoparticles}

Chemicals: The following reagents were purchased from Fishier Scientific: Ethanol, methanol, toluene, N, N-dimethylformamide (DMF), acetic acid, and cesium hydroxide. Molybdenum disulfide $(2 \mu \mathrm{m})$, polyvinyl pyrrolidone (MW=55,000), N-methyl-2pyrrolidone (NMP), L-ascorbic acid, sodium borohydride and silver nitrate were purchased from Sigma-Aldrich. 4-mercaptobenzoic acid (p-MBA) was purchased from TCI. All reagents were used as received, without further purification. $18.2 \mathrm{M} \Omega \cdot \mathrm{cm}$ deionized (DI) water was used.

\section{A. I. Synthesis of Two-dimensional $\mathrm{MoS}_{2}$}

Two-dimensional $\mathrm{MoS}_{2}$ was prepared by liquid exfoliation technique. $0.15 \mathrm{~g} \mathrm{MoS}_{2}$ powder dispersed in $150 \mathrm{~mL} \mathrm{~N}$-methyl-2-pyrrolidone was sonicated using probe sonicator (Qsonica, Q700 with 0.5 inch diameter tip) at 5 seconds on/off interval for 3 hours at a temperature below $15^{\circ} \mathrm{C} \cdot{ }^{1-3}$ The large un-exfoliated particles were removed by centrifugation (Beckman Coulter, Allegra 64R). The solution was centrifuged at 2,000 rpm for 10 minutes. The supernatant was then centrifuged for 10 minutes at $10,000 \mathrm{rpm}$ to precipitate the $\mathrm{MoS}_{2}$ sheets. The product was washed twice by dispersing in deionized (DI) water and precipitated by centrifugation at $10,000 \mathrm{rpm}$ for 10 minutes. The final product was dispersed in pure methanol.

\section{A. II. Synthesis of silver nanodisks (AgND)}

AgNDs were prepared using the simultaneous asymmetric multiple reduction technique (SMART). ${ }^{4} 0.60 \mathrm{~mL}$ of $60 \mathrm{mM} \mathrm{AgNO}$ aqueous solution was added to $200 \mathrm{~mL}$ of $0.145 \mathrm{mM}$ polyvinyl pyrrolidone aqueous solution, followed by $2 \mathrm{~mL}$ of $78 \mathrm{mM} \mathrm{L}-$ ascorbic acid. The AgNDs will be formed by dropping $0.124 \mathrm{~mL}$ of $5 \mathrm{mM} \mathrm{NaBH}_{4}$ aqueous 
solution to the resulting solution while swirling. The AgNDs were cleaned by centrifugation at $12,000 \mathrm{rpm}$ for 35 minutes and decanted. The precipitate was then dispersing in DI water and precipitated at by centrifugation for 20 minutes at 8,500 rpm. The AgNDs final product was dispersed in a mixture of $2 \mathrm{~mL}$ methanol and $4 \mathrm{~mL}$ chloroform.

\section{A. III. Synthesis of silver nanocluster (AgNCs)}

The $\mathrm{AgNC} \mathrm{M}_{4} \mathrm{Ag}_{44}\left(\mathrm{SC}_{6} \mathrm{H}_{4} \mathrm{COOH}\right)_{30}$ was synthesized using method reported earlier.5 In summary, $21 \mathrm{~mL} \mathrm{AgNO}_{3} 11.9 \mathrm{mM}$ aqueous solution was added to $12 \mathrm{~mL}$ MBA $83.33 \mathrm{mM}$ ethanoic solution while stirring. At this point the reaction mixture was a light yellow cloudy solution, which are the partially soluble $\operatorname{Ag}_{n} \mathrm{SR}_{\mathrm{n}+1}$ and $(\mathrm{AgSR})_{\mathrm{n}}$ precursors. Then the $\mathrm{pH}$ of the reaction mixture was adjust with $50 \% \mathrm{w} / \mathrm{v} \mathrm{CsOH}$ aqueous solution dropwise to 12 and the solution turned into a clear light yellow solution.

The precursor solution was then reduced with $9 \mathrm{~mL}$ ice cold $\mathrm{NaBH}_{4} 277.78 \mathrm{mM}$ aqueous solution dropwise with stirring over 30 minutes then stirred for 1 hour. The wine red final solution was conformed using UV/Vis spectra before centrifuged 5 min at $15 \mathrm{krpm}$ to remove any solid byproduct. DMF was added to the solution to precipitate the nanoclusters and then supernatant was removed by centrifugation and decanting before storage in fridge until use.

\section{B. Characterization of AgNCs}

\section{B. I. UV-visible absorption spectroscopy}

Solution-phase absorption spectra of the clusters were recorded in standard quartz cuvettes using a StellarNet dual detector super range spectrometer system. 


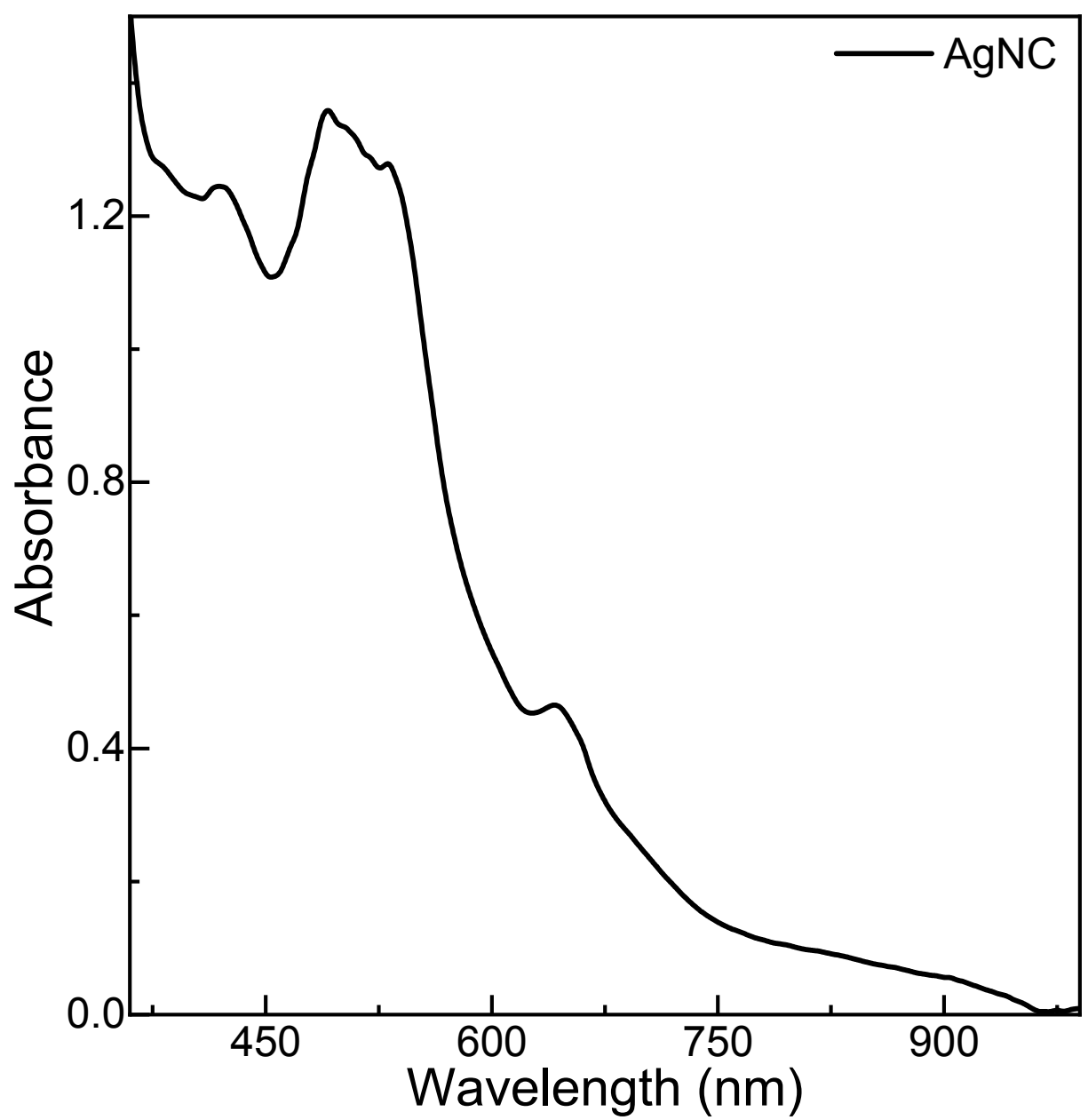

Figure S1. Optical absorption of $\mathrm{M}_{4} \mathrm{Ag}_{44}(\mathrm{p}-\mathrm{MBA})_{30}$. The spectrum was collected with final product protonated with acidic acid product and dissolved in DMF. The absorption spectrum of AgNCs dispersed in DMF displayed the characteristic peaks of $\mathrm{M}_{4} \mathrm{Ag}_{44} \mathrm{p}$ $\mathrm{MBA}_{30}$ reported earlier at $419 \mathrm{~nm}, 485 \mathrm{~nm}, 533 \mathrm{~nm}, 643 \mathrm{~nm} .^{5}$

\section{B. II. Electrospray-Ionization Mass Spectrometry (ESI-MS) analysis of}

\section{$\mathrm{Ag}_{44}\left(\mathrm{SC}_{6} \mathrm{H}_{4} \mathrm{COOH}\right)_{30}{ }^{4-}$}

For ESI-MS analysis, the silver nanoclusters must first to protonated to ensure that only core charge will be detached. About $0.5 \mathrm{mg}$ of the raw product was washed by dissolving in $100 \mu \mathrm{L}$ DI water and precipitated with $400 \mu \mathrm{L}$ DMF then removed the 
supernatant. The material was then protonated in $100 \mu \mathrm{L}$ DMF by adding acidic acid dropwise until dissolved then precipitated with toluene. The initially insoluble in DMF nanoclusters was rapidly dissolved into a deep red solution after protonated for 3 times which indicated it was fully protonated.

The protonated nanoclusters were then dissolved in $1 \mathrm{~mL}$ DMF with $0.1 \%$ acidic acid and directly infused into a mass spectrometer at $3 \mu \mathrm{L} / \mathrm{min}$ flow rate. All mass spectrometry data were collected on a maXis quadrupole time-of-flight mass spectrometer (Bruker Daltonik $\mathrm{GmbH}$ ) and operated in negative ionization. Instrumental parameters were maintained as following: capillary voltage, $3100 \mathrm{~V}$; end plate offset, $-500 \mathrm{~V}$; nebulizer, 0.3 Bar; Dry gas flow rate, $4 \mathrm{~L} / \mathrm{min}$; dry temperature, $120^{\circ} \mathrm{C}$; transfer funnel $1 \mathrm{RF}, 400.0$ Vpp; multipole RF, 400.0 Vpp; quadrupole ion energy, $3.0 \mathrm{eV}$; collision cell collision energy $5.0 \mathrm{eV}$; collision RF, $4000.0 \mathrm{Vpp}$; transfer time, $130.0 \mu$ s; pre pulse storage, 40.0 $\mu \mathrm{s}$. External calibration was performed in negative ionization mode in the range $800 \mathrm{m/z}$ " 6000 using a solution of cesium perfluoroheptanoate. All mass spectra were collected with rolling average of 10 scan and sample time of 1.5 second then averaged over 1 minute of data. The mass spectra were processed using Compass DataAnalysis software (Bruker Daltonik GmbH, version 4.3 Build 110.102.1532.) and the simulated isotopic patterns were generated within the software.

ESI-MS of the pronated AgNC identified several ion species that were all attributed to a single cluster size. The base peak ( $\mathrm{m} / \mathrm{z}$ 2335.4) was identified as $\mathrm{Ag}_{44} \mathrm{p}-\mathrm{MBA}_{30}{ }^{4-}$ as shown in Figure S2. This chemical formula was confirmed by matching the experimental and theoretical isotopic distributions (Fig. S2 inset). The peak next to it was identified as the $\mathrm{Ag}_{44} \mathrm{p}-\mathrm{MBA}_{30}{ }^{4-}$ with one of the $\mathrm{p}-\mathrm{MBA}$ proton exchanged by a $\mathrm{Na}^{+}$. The peak at 2795.9 is 
a fragment of $\mathrm{Ag}_{44} \mathrm{p}-\mathrm{MBA}_{30}{ }^{4-}, \mathrm{Ag}_{44} \mathrm{p}-\mathrm{MBA}_{30}{ }^{4-}$ is known to spontaneously break into $\mathrm{Ag}_{43} \mathrm{p}-\mathrm{MBA}_{28}{ }^{3-}$ and $\mathrm{Ag}_{1} \mathrm{p}-\mathrm{MBA}_{2}$ during desolvation. ${ }^{1-5}$

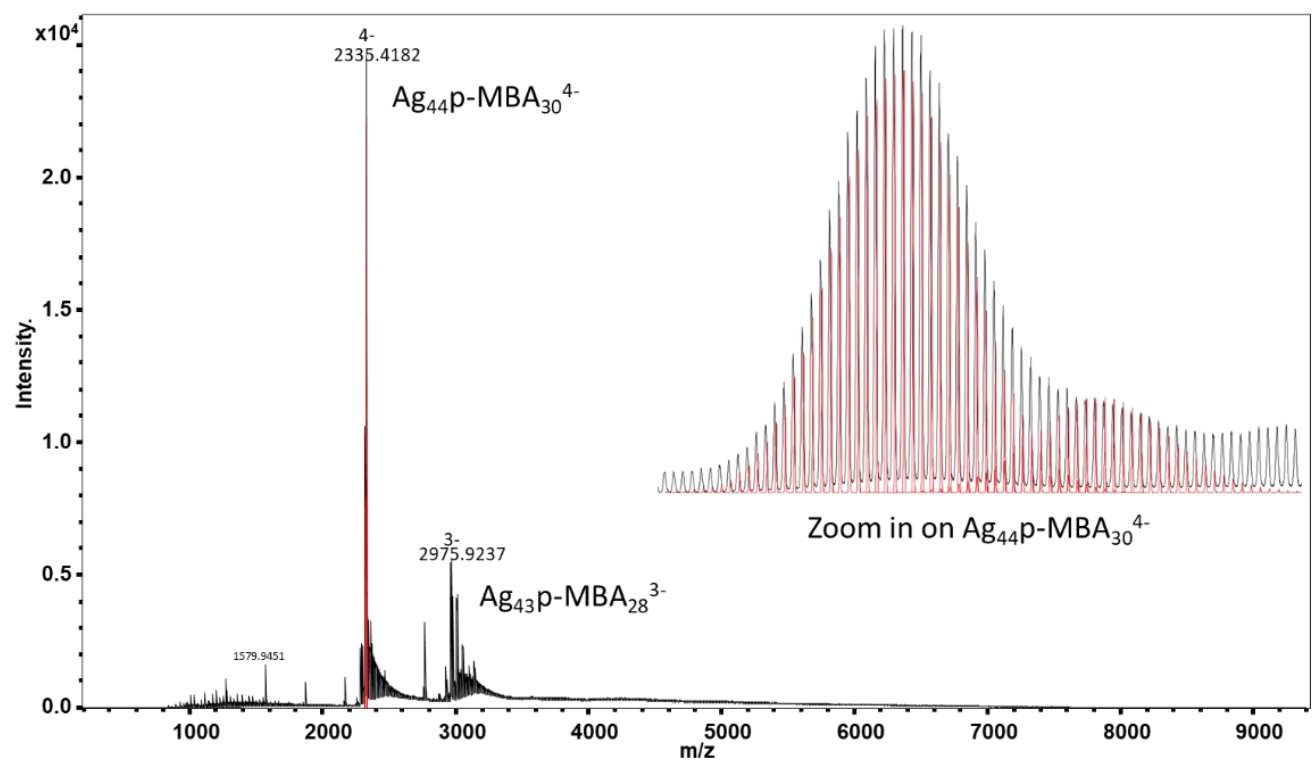

Figure S2. ESI-MS of $\mathrm{Ag}_{44} \mathrm{p}-\mathrm{MBA}_{30}{ }^{4-}$. Peaks around $3000 \mathrm{~m} / \mathrm{z}$ are fragments with 3- charge state, mainly $\mathrm{Ag}_{43} \mathrm{p}-\mathrm{MBA}_{28}{ }^{3-}$. Inset: zoom in on 2335 Da peak, with the isotope distribution of $\left[\mathrm{Ag}_{44} \mathrm{p}-\mathrm{MBA}_{30}\right]^{4-}$ and $\left[\mathrm{Ag}_{44} \mathrm{p}-\mathrm{MBA}_{30}-\mathrm{H}+\mathrm{Na}\right]^{4-}$ simulated with Bruker DataAnalysis software in red.

\section{B. III. TEM of the AgNCs}

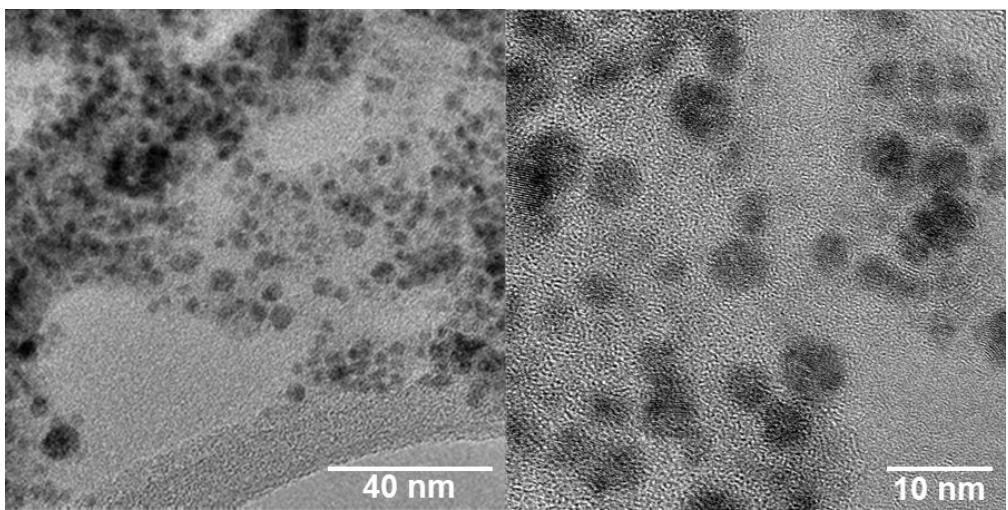

Figure S3. TEM of the AgNCs

\section{Coating AgNC on top of $\mathrm{MoS}_{2}$ slides for optical analysis}

The silver nanoclusters used to optical measurement and interact with $\mathrm{MoS}_{2}$ nanosheets were first protonated like the sample analyzing with MS with method as 
mentioned before. The $0.5 \mathrm{mg} / \mathrm{mL} \mathrm{DMF}$ solution of $\mathrm{AgNC}$ was then sprayed on to microscope glass slides, that were spin coated with $\mathrm{MoS}_{2}$, using SunCollect MALDI spotter/sprayer (SunChrom, model 06172). Instrumental parameters were maintained as following: distance in $\mathrm{X}, 0.50 \mathrm{~mm}$, distance in $\mathrm{Y}, 2.00 \mathrm{~mm}$, time between layers, $5 \mathrm{~s}$, speed $\mathrm{x}$, medium 1 , speed $\mathrm{y}$, medium 5 . The solution flow rate was set to $2 \mathrm{uL} /$ minute with 30 PSI $\mathrm{N}_{2}$ as drying gas. 3 slides with 1, 3 and 5 layer of AgNC solution on top of the spin coated $\mathrm{MoS}_{2}$ were prepared. The parameters were optimized to make sure the solution dries instantly so no $\mathrm{MoS}_{2}$ re-dispersing caused by solvent droplets.

\section{Theoretical calculation}

\section{Finite-difference time-domain (FDTD) simulation}
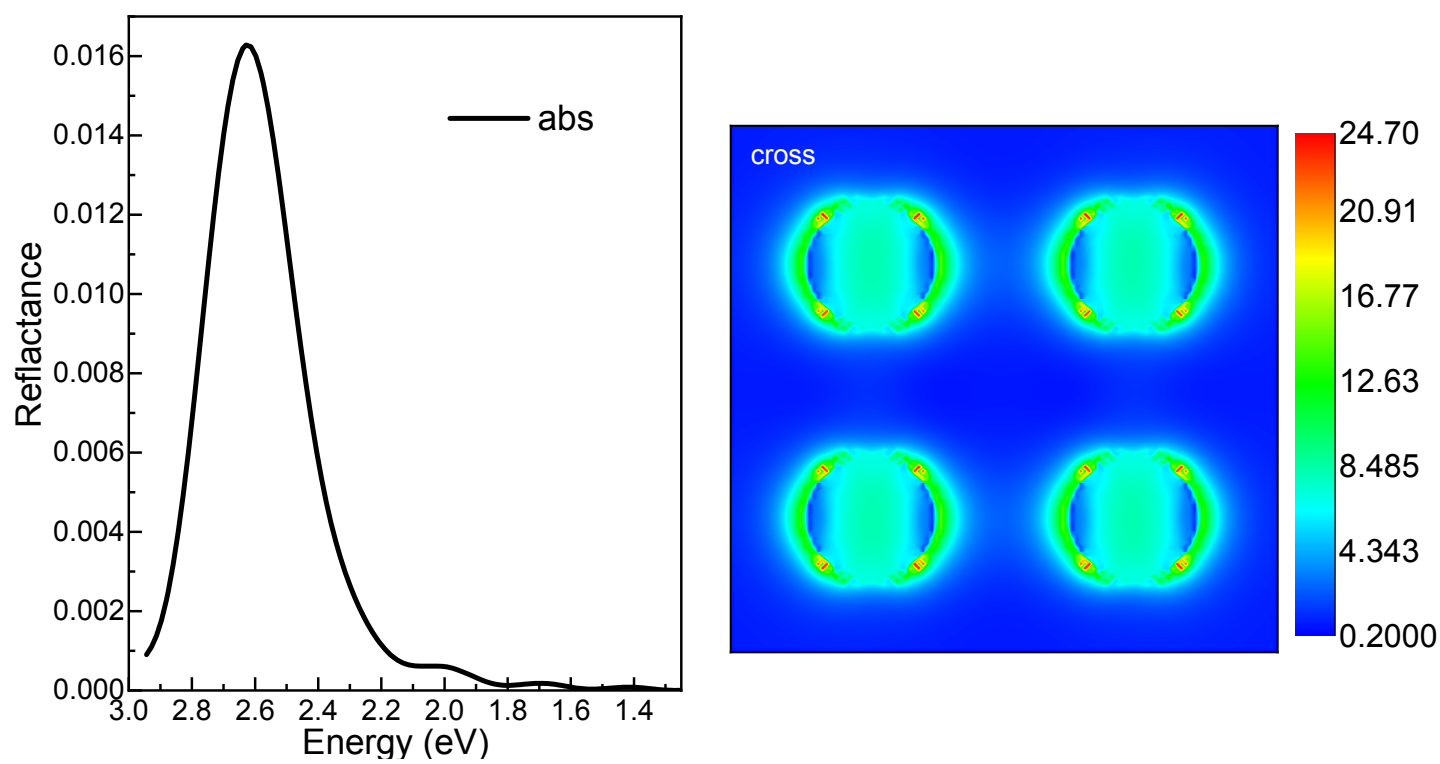

Figure S4. Simulated LSPR spectrum of AgNDs on glass and the plasmon field distribution 

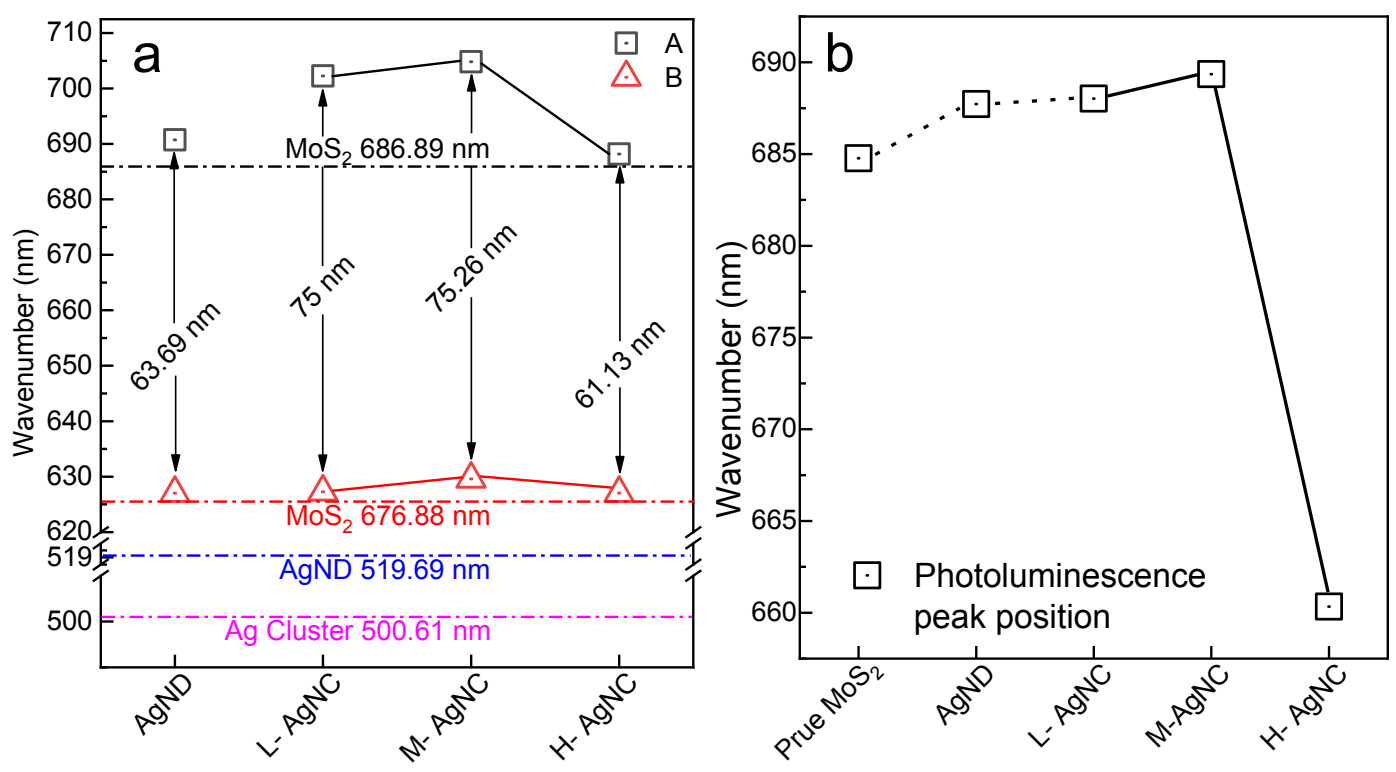

Figure S5. a) The values of absorption spectrum's A and B absorption peaks of $\mathrm{MoS}_{2}$ and $\mathrm{MoS}_{2}$ integrated with AgND or AgNCs of different magnitudes in nanometer. b) The value of the PL peak position of MoS2 and MoS2 integrated with AgND and AgNCs of different concentrations.

\section{REFERENCES}

1. Coleman, J. N.; Lotya, M.; O'Neill, A.; Bergin, S. D.; King, P. J.; Khan, U.; Young, K.; Gaucher, A.; De, S.; Smith, R. J.; Shvets, I. V.; Arora, S. K.; Stanton, G.; Kim, H. Y.; Lee, K.; Kim, G. T.; Duesberg, G. S.; Hallam, T.; Boland, J. J.; Wang, J. J.; Donegan, J. F.; Grunlan, J. C.; Moriarty, G.; Shmeliov, A.; Nicholls, R. J.; Perkins, J. M.; Grieveson, E. M.; Theuwissen, K.; McComb, D. W.; Nellist, P. D.; Nicolosi, V. Two-Dimensional Nanosheets Produced by Liquid Exfoliation of Layered Materials. Science (Washington, DC, U. S.) 2011, 331 (6017), 568-71.

2. Chhowalla, M.; Shin, H. S.; Eda, G.; Li, L. J.; Loh, K. P.; Zhang, H. The Chemistry of Two-Dimensional Layered Transition Metal Dichalcogenide Nanosheets. Nat. Chem. 2013, 5 (4), 263-75.

3. Obiakara, C.; Mahmoud, M. A. Electromagnetic Plasmonic Field of Nanoparticles Tune the Band Gap of Two-Dimensional Semiconducting Materials. J. Mater. Chem. C 2019, 7 (12), 3675-3687.

4. Mahmoud, M. A. Simultaneous Reduction of Metal Ions by Multiple Reducing Agents Initiates the Asymmetric Growth of Metallic Nanocrystals. Cryst. Growth Des. 2015, 15 (9), 4279-4286.

5. Desireddy, A.; Conn, B. E.; Guo, J.; Yoon, B.; Barnett, R. N.; Monahan, B. M.; Kirschbaum, K.; Griffith, W. P.; Whetten, R. L.; Landman, U.; Bigioni, T. P. Ultrastable Silver Nanoparticles. Nature (London, U. K.) 2013, 501 (7467), 399-402. 